\title{
INDIVÍDUO E TRABALHO: CONTRIBUIÇÕES DE MARCUSE A ESSA RELAÇÃO.
}

Gabriel Ramponi*

\section{Resumo:}

A pesquisa tem por objeto a relação entre indivíduo e trabalho, e, para tal, se apoiará em obras de Herbert Marcuse para o seu desenvolvimento e problematização. Nesse sentido, será dada atenção especial a duas de suas obras: Razão e Revolução e Eros e Civilização. Discutindo, respectivamente, conceitos de Georg Wilhelm Friedrich Hegel e de Sigmund Freud, Marcuse oferece diferentes perspectivas ao estudo de nosso objeto. Portanto, a pesquisa pretende descrever como Marcuse enxerga a relação entre indivíduo e trabalho através do prisma de cada um dos autores citados. A seguir, pretende-se estabelecer a transição entre o panorama conceitual construído, baseado no trabalho alienado e no princípio de desempenho, e um outro estado, um "estado estético" (MARCUSE, 2010:170), para além do princípio de desempenho. Por fim, pretende-se discutir e problematizar as potencialidades do trabalho artístico como superação do trabalho alienado, dialogando com o potencial político que Marcuse enxerga na arte, além de se propor que uma superação dessa magnitude deve considerar como possibilidade a transformação do indivíduo em artista, no sentido de criador, em contraste com o trabalho alienado, em que neste se faz limitado a um "instrumento de trabalho", e, portanto, apenas reprodutor. Assim, entende-se que a relação do indivíduo com a arte deve ser ativa.

Palavras-chave: Indivíduo, Trabalho, Arte, Marcuse.

\section{Texto:}

"Se o indivíduo não tem a capacidade nem a possibilidade de ser por si mesmo, os termos da Psicologia convertem-se nos termos das forças da sociedade que definem a psique" (MARCUSE, 2010: 25).

Este pequeno excerto retirado do prefácio da primeira edição de Eros e Civilização, demonstra a tendência de Herbert Marcuse, assim como outros membros do Instituto para Pesquisa Social, comumente chamada "Escola de Frankfurt", de aliar a Psicologia, além de outros campos do

\footnotetext{
* Unifesp, texto referente à projeto de Mestrado, inédito.
} 
conhecimento, à Teoria Social. Isso se deve à preocupação do autor em construir uma teoria de mudança social baseada na satisfação individual (KELLNER, 1994:3). A partir do mesmo pressuposto do autor, quer dizer, de que a Teoria Social deve se orientar segundo a satisfação individual, a pesquisa tem por objetivo então se aprofundar na relação entre o indivíduo e as "forças de sociedade" que o dão forma. Mas, que "forças da sociedade" são essas?

Como já afirmamos, Marcuse busca uma teoria interdisciplinar. Nesse sentido, o autor utiliza desde a psicanálise freudiana até a fortuna crítica hegeliana, num esforço de compreender as forças da sociedade supracitadas, assim como, e principalmente, a relação destas com o indivíduo. Porém, mesmo nesse movimento teórico do autor, um conceito permanece: o trabalho.

“A civilização é, acima de tudo, progresso no trabalho - quer dizer, trabalho para o agenciamento e ampliação das necessidades da vida" (MARCUSE, 2010:85). Podemos assim dizer que para Marcuse, a história da civilização é a história do homem, e não podem ser dissociadas da atividade de trabalho. Poder-se-ia considerar até que a evolução do próprio homem está intimamente ligada a evolução das formas de trabalho. Descrever o papel que o trabalho exerce na sociedade contemporânea, além de sua forma de organização, passa a ser, então, fundamental à compreensão do indivíduo contemporâneo. No sentido de se aprofundar e tentar descrever, então, a relação entre indivíduo e trabalho, a pesquisa pretende abordar dois livros de Marcuse em especial: Eros e Civilização, e Razão e Revolução.

Em Razão e Revolução, Marcuse desenvolve noções fundamentais do pensamento de Hegel, passando por diversos pontos de sua teoria, inclusive sobre o trabalho e sua relação com o indivíduo. Através do prisma dialético hegeliano, essa relação é vista tanto em termos de sua efetividade quanto de suas potencialidades. Quer dizer, Hegel enxerga que

[...] na medida em que o trabalho deixa de ser a autorealização do indivíduo, e passa a ser sua autonegação a relação entre as necessidades particulares e o trabalho, e entre as necessidades e o trabalho do todo toma a forma de uma 'interdependência cega e incalculável'. A integração dos indivíduos conflitantes, através do trabalho abstrato e da troca, estabelece pois 'um vasto sistema comunitário e de mútua interdependência, uma vida ativa de mortos' (MARCUSE, 2004:78).

Porém, ao mesmo tempo, admite o potencial interno a atividade de trabalho: 
Através do seu trabalho o homem vence a separação entre os mundos objetivo e subjetivo: ele transforma a natureza em um meio adequado ao seu próprio desenvolvimento. Quando os objetos são tomados e fabricados pelo trabalho, tornam-se parte do sujeito que está apto para neles reconhecer suas necessidades e desejos. Através do trabalho, além do mais, o homem sai daquela existência atomizada na qual, como um indivíduo, se opunha a todos os outros indivíduos; ele torna-se membro de uma comunidade. Em virtude do seu trabalho, ele se transforma em um universal, e isto porque o trabalho, por sua própria natureza, é uma atividade universal: seus produtos são permutáveis entre todos os indivíduos (MARCUSE, 2004: 77).

Apreender, portanto, o movimento do Conceito de trabalho para Hegel, e com isso, a sua relação com o indivíduo, será o núcleo do primeiro momento da pesquisa. Configurando um capítulo, tentaremos entender, por exemplo, o que caracteriza o trabalho como uma atividade universal, capaz de criar, na visão de Hegel, uma comunidade; também deverá ser abordado o que Hegel tem por "externalização da consciência", mais especificamente a relação entre o trabalho alienado e o indivíduo alienado. Portanto, o primeiro capítulo será responsável por fazer uma descrição do modo como Marcuse aborda a relação entre trabalho e indivíduo através do prisma hegeliano.

Se admitirmos que "o trabalho que criou e ampliou a base material da civilização foi principalmente labuta, trabalho alienado, penoso e desagradável - e ainda é" (MARCUSE, 2010:88), e assumirmos que o trabalho alienado desemboca em uma "vida ativa de mortos", quer dizer, não é uma atividade de realização individual, em que medida então a relação entre o trabalho e o indivíduo libera o indivíduo à fruição de suas capacidades ou de seus prazeres?

Marcuse nos mostra que o indivíduo

[...] tem de trabalhar para viver, e esse trabalho não exige apenas oito, dez, doze horas diárias do seu tempo e, portanto, uma correspondente divisão de energia, mas também durante essas horas e as restantes, um comportamento em conformidade com os padrões e a moral do princípio de desempenho (MARCUSE, 2010:92).

Com isso, entendemos que a relação do indivíduo e do trabalho alienado, sob o princípio de desempenho, não permite ao indivíduo nenhuma esfera verdadeiramente dissociada do trabalho; 
quer dizer, o indivíduo vive como instrumento do trabalho. Esse processo ocorre sob as determinações do que Marcuse toma por "princípio de desempenho".

A partir da visão histórica do conceito de princípio de realidade de Freud, Marcuse desenvolve o conceito de princípio de desempenho, que seria o princípio de realidade histórico ao qual estaríamos submetidos dado o contexto da sociedade industrial. Basearemo-nos na obra Eros $e$ Civilização, então, para fazer uma descrição de como Marcuse articula os conceitos freudianos para demonstrar como o trabalho alienado domina a existência do indivíduo de uma forma a englobar todas as esferas da vida, limitando o indivíduo a instrumento de trabalho. Esse será o movimento do segundo capítulo.

Tendo sido realizadas, através da ótica de Marcuse, as descrições referentes aos conceitos hegelianos em Razão e Revolução e aos freudianos em Eros e Civilização, buscamos estabelecer uma transição entre o trabalho alienado, relacionado com um "Eros consideravelmente sublimado e debilitado" (MARCUSE, 2010:88), e outra forma de organização de trabalho, relacionada ao "Eros Órfico" (MARCUSE, 2010).

A transição deverá se basear no capítulo 9 de Eros e Civilização, "Dimensão Estética", já que "a disciplina da estética instala a ordem da sensualidade contra a ordem da razão", negando assim também o princípio de desempenho. Isso leva Marcuse a vislumbrar um princípio de realidade nãorepressivo:

[...] a eliminação da mais-repressão tenderia per se a eliminar não a atividade laboral, mas a organização da existência humana como instrumento de trabalho. Sendo assim, a emergência de um princípio de realidade não-repressiva modificaria, mas não destruiria, a organização social do trabalho; a libertação de Eros poderia criar novas e duradouras relações de trabalho (MARCUSE, 2010:143).

Portanto, a transição, que comporá o terceiro capítulo, se baseará nos arquétipos de Orfeu e Narciso e na exposição do que este seria, do mesmo modo como se relaciona a esse movimento, a dimensão estética. Assim, poderemos chegar ao quarto e último capítulo, em que desenvolveremos a noção do trabalho artístico como uma possibilidade de superação do trabalho alienado.

Acreditando que a grande arte pudesse inspirar a busca por existências mais livres (KELLNER, 1994:9), Marcuse insiste no potencial político da arte como meio de superação do princípio de 
desempenho; além disso, a arte também exerceria papel central na forma de organização social em que o trabalho alienado fosse superado. Mas para chegarmos à isso, devemos entender o que significa para Marcuse a "emancipação" do trabalho alienado:

\begin{abstract}
A teoria da alienação demonstrou o fato de que o homem não se realiza em seu trabalho, que a sua vida se tornou um instrumento de trabalho, que o seu trabalho e os respectivos produtos assumiram uma forma e um poder independentes dele com indivíduo. Mas a emancipação desse estado parece requerer não que se impeça a alienação, mas que esta se consuma; não a reativação da personalidade reprimida e produtiva, mas a sua abolição. A eliminação das potencialidades humanas do mundo de trabalho (alienado) cria as precondições para a eliminação do trabalho do mundo das potencialidades humanas (MARCUSE, 2010:103).
\end{abstract}

Nesse sentido, Marcuse acredita que "quanto mais completa for a alienação do trabalho, tanto maior é o potencial de liberdade; a automação total seria o ponto ótimo" (MARCUSE, 2010:144). A aposta do autor, então, é que, libertado da labuta, o homem poderia viver em uma civilização livre, e que criasse indivíduos livres:

O próprio indivíduo livre deve originar a harmonia entre a gratificação individual e a universal. Numa civilização verdadeiramente livre, todas as leis são promulgadas pelos próprios indivíduos: 'dar liberdade pela liberdade é a lei universal' do 'estado estético'; numa civilização verdadeiramente livre, 'a vontade do todo' só se cumpre 'através da natureza do indivíduo'. A ordem só é liberdade se fundada e mantida pela livre gratificação dos indivíduos. (MARCUSE, 2010: 170).

Portanto, no quarto capítulo, devemos chegar à conclusão do autor, no sentido de ter perpassado os pontos mais importantes da conceituação, tanto do indivíduo como do trabalho, através do prisma que Marcuse nos oferece, de modo a que tenhamos estabelecido a relação entre os conceitos. Além disso, espera-se construir as bases para entendermos a transição teórica que o autor estabelece entre o princípio de realidade a que estamos subordinados e outro, organizado segundo outros pressupostos. Isso é o que nos interessa ao final da pesquisa: desenvolver as noções que permeiam o "estado estético" de Orfeu e Narciso, e como o trabalho alienado pudesse ser superado pelo trabalho artístico, trabalho esse de criação, e não de reprodução. 
Bibliografia:

FREUD, Sigmund. O Mal-estar na Civilização. 1a Edição. São Paulo: Penguin Classics Companhia das Letras, 2011.

HEGEL, G. W. F.. Fenomenologia do Espírito. Petrópolis, RJ: Vozes: Bragança Paulista: Editora Universitária São Francisco, 2007.

. Filosofia da História. Brasília: UNB, 2008.

. Ciência da Lógica (excertos). São Paulo: Barcarola, 2011.

HYPPOLITE, Jean. Gênese e estrutura da Fenomenologia do Espírito de Hegel, São Paulo: Discurso Editorial, 1999.

KELLNER, Douglas. A Marcuse Renaissance? Disponível em: http://pages.gseis.ucla.edu/faculty/kellner/essays/marcuserenaissance.pdf . Acesso em: 14/05/2014 MARCUSE, Herbert. Cultura e psicanálise. São Paulo: Paz e Terra, 2001.

Razão e Revolução: Hegel e o advento da teoria social. 5a Edição. São Paulo: Paz e Terra, 2004.

. Dimensão Estética. Lisboa: Edições 70, 1999.

. Eros e Civilização: uma interpretação filosófica do pensamento de Freud. Rio de Janeiro: LTC, 2010.

. Ideologia da Sociedade Industrial. Rio de Janeiro: Zahar, 1967.

MARX, Karl. Manuscritos econômico-filosóficos. São Paulo: Boitempo, 2010. 